\title{
THE EFFECTS OF REDUCED CARDIAC SYMPATHETIC TONE ON MYOCARDIAL FUNCTION*
}

\author{
By JOHN W. ECKSTEIN † AND A. W. HORSLEY $\ddagger$ \\ (From the Hemodynamic Laboratory, Cardiovascular Research Laboratories, Department of \\ Internal Medicine, State University of Iozva College of Medicine, \\ Iowa City, Iowa)
}

(Submitted for publication June 22, 1960; accepted November 3, 1960)

Stimuli mediated over cardiac sympathetic nerves increase the work output of the heart (1) and the contractility of the myocardium (2). Such stimuli increase ventricular performance so that more external work is produced at a lower filling pressure (3). Stimuli mediated over the vagus nerves appear to decrease ventricular performance (4). Recent work indicates that sympathetic stimulation increases and that vagal stimulation decreases the vigor of atrial contraction (5). The data from these same experiments show also that the relation between mean atrial pressure and stroke work is determined by atrial as well as ventricular function (5).

When one considers that autonomic stimuli modify ventricular filling time as well as ventricular performance it becomes apparent that the regulation of the cardiac output in the normal subject must involve a very delicate balance between the autonomic and humoral factors that affect the myocardium directly, and all of the factors that influence the availability of blood to the heart. It is not surprising that it has been difficult to show a distinct correlation between mean atrial or end-diastolic pressure and cardiac output in dogs with closed chests (6-9) and in man (10-13).

The experiments to be reported here were carried out in very lightly anesthetized dogs with closed chests and intact circulations. They show that the heart, operating with its rate controlled and in the presence of reduced autonomic tone, increases its output when mean atrial pressure is increased. They also show that cardiac output at a given heart rate and a given atrial pressure is

* Supported by a research grant (H-2644) from the National Heart Institute, Bethesda, Md., and aided by a grant from the Iowa Heart Association.

$\dagger$ Established Investigator of the American Heart Association.

$\ddagger$ Alfred Stengel Research Fellow of the American College of Physicians. reduced when existing activity of the cardiac sympathetic nerves is reduced.

\section{METHODS}

Mongrel dogs were lightly anesthetized with 100 to $150 \mathrm{mg}$ of thiopental sodium (Pentothal Sodium) and then given gallamine triethiodide (Flaxedil), $5.0 \mathrm{mg}$ per $\mathrm{kg}$ intravenously. A cuffed endotracheal tube was inserted immediately through the larynx and connected to a fixed-volume respiratory pump. Both vagus nerves, the left carotid artery and the right external jugular vein at its bifurcation were exposed through three small incisions within the next 10 to 15 minutes. At this point a second small dose of thiopental (about $50 \mathrm{mg}$ ) was given and bilateral vagotomies were done. The animal was then turned into the left lateral position and a doublelumen catheter (both openings at the tip) was manipulated through a branch of the external jugular vein under fluoroscopic visualization until its tip lay in the main pulmonary artery. A second catheter with a single lumen and an electrode near the tip was introduced through the other branch of the jugular vein and placed so that its tip lay in the right atrium near the junction with the superior vena cava. The locations of the tips of both catheters were marked carefully during fluoroscopy with the dog supine and lying on the left side. An electrode was attached to the chest wall immediately opposite the tip of the intra-atrial catheter. Statham strain gages were connected to the intra-atrial catheter and to one lumen of the pulmonary arterial catheter. The gages were mounted vertically on the sides of the dog board so that their reference levels coincided with lines formed by the intersection of vertical and horizontal planes passing through the tips of the catheters. The gages were mounted on swivels and kept in the vertical position when the dog board was tilted so that the same relationship between catheter tip and gage would be maintained. Needles were inserted into the left carotid and femoral arteries and the left femoral vein. The needle in the carotid artery was connected through small-bore nylon tubing to the cuvet of a Gilford densitometer. The needle in the femoral artery was connected to a strain gage through a short piece of polyethylene tubing. The needle in the femoral vein was connected to a stopcock and used for intravenous administration of drugs. Endexpiratory $\mathrm{CO}_{2}$ concentration was monitored with a Liston-Becker $\mathrm{CO}_{2}$ analyzer. The other lumen of the 
pulmonary arterial catheter was used for injections of indocyanine green dye. Dye curves were obtained by drawing blood from the left carotid artery through the densitometer with a constant speed pump. Dye curves, end-expiratory $\mathrm{CO}_{2}$ concentrations and blood pressures were recorded simultaneously with a Sanborn direct-writing oscillograph.

After the needles and catheters were in position, the animals were blindfolded and touched as infrequently as possible. All unnecessary noise was avoided. Ventilation was adjusted so that end-expiratory $\mathrm{CO}_{2}$ concentration was about 4 per cent. The rate and depth of breathing were not changed after this initial adjustment. Twenty to 30 minutes was allowed for blood pressures and heart rate to become stable after the animal was prepared. This, in addition to the time required for preparation, was ample time for nearly complete disappearance of the thiopental effects $(14,15)$. Injections of indocyanine green dye were then made into the pulmonary artery at 5 - to 10 -minute intervals. The resulting dye curves were recorded and examined carefully. After appearance time, peak concentration time and general configuration became stable, the dog was tilted into the $20^{\circ}$ head-down position. Four to 7 minutes was al lowed for blood pressure and heart rate to become stable again, then two dye curves were obtained and the dog board was returned to the horizontal position. After restabilization of the heart rate and blood pressure, 15.0 $\mathrm{mg}$ of the ganglionic blocking agent, trimethidinium methosulphate (Ostensin, Wy-1395) (16-19), was given intravenously. Ten to 15 minutes more was allowed for blood pressures and heart rate to level off. Observations were then made in the supine and head-down positions in the same manner as before trimethidinium. After the second dye curve was obtained with the dog tilted, the heart rate was restored as nearly as possible to that existing before the drug, by stimulating the heart with a 2 to $4 \mathrm{msec}$ square wave of 2 to $5 \mathrm{v}$ through the intra-atrial and chest wall electrodes. Two more curves were ob- tained in quick succession at the restored heart rate with the animal head-down.

Electrically integrated mean right atrial and pulmonary arterial blood pressures were recorded throughout each dye curve. Mean systemic arterial pressure was recorded immediately before and after obtaining each curve. Phasic arterial pressure was registered during the curve so that heart rate could be counted. Fifty $\mathrm{ml}$ of blood was taken at the beginning of the experiment for calibration of the densitometer. The blood required for inscription of each curve was returned to the dog immediately by reversing the motor on the withdrawal pump. Dye solutions were made up before the experiment, and a small amount of blood was added so that the dye in the injectate would be bound to plasma. This prevents the change in optical density with time that would occur in an aqueous solution. Three-point calibration curves were used in each experiment. Approximately $2.5 \mathrm{mg}$ of dye was used for injection. Background dye in the blood was "zeroed" out with the variable density wedge on the densitometer before each injection. The numerical setting of the wedge corresponding to the background was recorded for each determination. The amount of background dye could be estimated from this information, which made it possible to allow an appropriate amount of time between groups of injections to insure against excessive accumulations of the dye in the blood.

The values to be reported are the final observations obtained in the supine and head-down positions. The values reported with pacing of the heart are the first observations made after the heart rate nearest the control rate was established. All systemic arterial pressures are referred to right atrial level. Pulmonary arterial and atrial pressures are referred to the tips of the catheters. The strain gages were calibrated with a water manometer graduated in millimeters of mercury. Zero suppression circuits and high sensitivities were used so that small changes in right atrial and pulmonary arterial

TABLE I

Responses to increased right atrial pressure before administration of a ganglionic blocking agent *

\begin{tabular}{|c|c|c|c|c|c|c|c|c|c|c|c|c|c|c|c|c|c|c|c|c|c|}
\hline \multirow[b]{2}{*}{ Dog } & \multirow[b]{2}{*}{ Wt } & \multicolumn{2}{|c|}{$\mathrm{RA}_{\mathrm{m}}$} & \multicolumn{2}{|c|}{$\mathrm{PA}_{\mathrm{m}}$} & \multicolumn{2}{|c|}{$\mathrm{SA}_{\mathrm{m}}$} & \multicolumn{2}{|c|}{ HR } & \multicolumn{2}{|c|}{$\mathrm{CO}$} & \multicolumn{2}{|c|}{ SV } & \multicolumn{2}{|c|}{ RVMW } & \multicolumn{2}{|c|}{ RVSW } & \multicolumn{2}{|c|}{ LVMW } & \multicolumn{2}{|c|}{ LVSW } \\
\hline & & $\mathrm{S}$ & $\mathrm{HD}$ & $\mathrm{s}$ & $\mathrm{HD}$ & $S$ & $\mathrm{HD}$ & $\mathrm{S}$ & HD & $S$ & $\mathrm{HD}$ & $\mathrm{S}$ & $\mathrm{HD}$ & $\mathrm{s}$ & $\mathrm{HD}$ & $S$ & $\mathrm{HD}$ & $S$ & HD & $S$ & $\mathrm{HD}$ \\
\hline & $\mathrm{kg}$ & \multicolumn{2}{|c|}{$m m \mathrm{Hg}$} & \multicolumn{2}{|c|}{$m m \mathrm{Hg}$} & \multicolumn{2}{|c|}{$m m \mathrm{Hg}$} & \multicolumn{2}{|c|}{ beats/min } & \multicolumn{2}{|c|}{$L / \min$} & \multicolumn{2}{|c|}{$m l$} & \multicolumn{2}{|c|}{ units } & \multicolumn{2}{|c|}{ units } & \multicolumn{2}{|c|}{ units } & \multicolumn{2}{|c|}{ units } \\
\hline 1 & 23.9 & 4.5 & 5.5 & 15.5 & 18.0 & 153 & 171 & 162 & 168 & 3.0 & 3.1 & 19 & 18 & 33 & 39 & 0.20 & 0.23 & 438 & 505 & 2.7 & 3.0 \\
\hline 2 & 18.3 & 2.7 & 3.9 & 13.0 & 12.5 & 148 & 156 & 248 & 244 & 2.3 & 2.4 & 9 & 10 & 24 & 21 & 0.10 & 0.09 & 328 & 359 & 1.3 & 1.5 \\
\hline 3 & 17.5 & 0.5 & 1.3 & 13.8 & 16.3 & 150 & 159 & 212 & 216 & 2.6 & 2.7 & 12 & 13 & 34 & 41 & 0.16 & 0.19 & 382 & 419 & 1.8 & 1.9 \\
\hline 4 & 19.0 & 3.1 & 5.4 & 16.4 & 18.5 & 137 & 135 & 224 & 220 & 2.4 & 2.4 & 11 & 11 & 32 & 31 & 0.14 & 0.14 & 315 & 305 & 1.4 & 1.4 \\
\hline 5 & 16.0 & 2.5 & 3.2 & 16.0 & 18.0 & 155 & 165 & 152 & 152 & 2.4 & 2.4 & 16 & 16 & 32 & 33 & 0.21 & 0.22 & 360 & 382 & 2.4 & 2.5 \\
\hline 6 & 20.5 & 5.1 & 6.5 & 14.8 & 16.6 & 137 & 165 & 174 & 180 & 2.3 & 2.4 & 13 & 13 & 22 & 24 & 0.13 & 0.13 & 298 & 374 & 1.7 & 2.1 \\
\hline 7 & 21.7 & 6.0 & 8.0 & 16.5 & 19.2 & 158 & 153 & 180 & 188 & 2.8 & 2.9 & 16 & 15 & 29 & 32 & 0.16 & 0.17 & 419 & 413 & 2.3 & 2.2 \\
\hline 8 & 17.5 & 2.3 & 4.8 & 12.3 & 18.0 & 132 & 137 & 200 & 180 & 2.2 & 2.3 & 11 & 13 & 22 & 30 & 0.11 & 0.17 & 280 & 296 & 1.4 & 1.6 \\
\hline 9 & 21.8 & 3.2 & 3.8 & 8.0 & 12.4 & 123 & 111 & 228 & 208 & 2.6 & 2.8 & 11 & 13 & 15 & 24 & 0.07 & 0.12 & 305 & 293 & 1.3 & 1.4 \\
\hline 10 & 17.0 & 4.1 & 5.3 & 13.3 & 14.2 & 127 & 128 & 208 & 200 & 2.4 & 2.3 & 12 & 12 & 22 & 20 & 0.11 & 0.10 & 289 & 276 & 1.4 & 1.4 \\
\hline
\end{tabular}

${ }^{*} \mathrm{RA}_{\mathrm{m}}$, right atrial mean pressure; $\mathrm{PA}_{\mathrm{m}}$, pulmonary arterial mean pressure; $\mathrm{SA}$, systemic arterial mean pressure; $\mathrm{HR}$, heart rate; $\mathrm{CO}$, cardiac output; SV, stroke volume; RVMW, right ventricular minute work index; RVSW, right ventricular stroke work index; LVMW, left ventricular minute work index; LVSW, left ventricular stroke work index : $\mathrm{S}$, supine position; HD, head-down position. 
mean pressures would cause large deflections on the recording paper. In most cases the sensitivity of the transducer-amplifier system was such that a pressure of $1 \mathrm{~mm}$ $\mathrm{Hg}$ caused a deflection of $1 \mathrm{~cm}$. The respiratory variation in pressure was very constant so that directional changes in right atrial and pulmonary arterial pressure could be recorded with exactness. Mean pressures were obtained by electrical integration of the output of the strain gages. Because of the sensitivity of the system and the constancy of ventilation, it was felt that mean atrial and pulmonary arterial pressures should be read in millimeters of $\mathrm{Hg}$, using one decimal figure. Cardiac output was calculated by the Stewart-Hamilton method. Right ventricular minute work index was calculated according to the formula $\left(\mathrm{PA}_{\mathrm{m}}-\mathrm{RA}_{\mathrm{m}}\right) \times \mathrm{CO}$. Left ventricular minute work index was calculated according to the formula $\left(\mathrm{SA}_{\mathrm{m}}-\mathrm{LA}_{\mathrm{m}}\right) \times \mathrm{CO}$. Stroke work index was equal to minute work index divided by heart rate. All indices of cardiac work are expressed in arbitrary units. $\mathrm{PA}_{\mathrm{m}}$ is pulmonary arterial mean pressure in millimeters of $\mathrm{Hg} . \mathrm{RA}_{\mathrm{m}}$ is right atrial mean pressure in millimeters of $\mathrm{Hg}$. $\mathrm{CO}$ is cardiac output in liters per minute. $\mathrm{SA}_{\mathrm{m}}$ is systemic arterial mean pressure in millimeters of $\mathrm{Hg}$, and $\mathrm{LA}_{m}$ is an approximation of left atrial mean pressure, also in millimeters of $\mathrm{Hg}$. Left atrial pressure was not measured. An arbitrary approximation of the left atrial pressure was taken as right atrial pressure plus $2.5 \mathrm{~mm} \mathrm{Hg}$.

The data were analyzed according to methods described by Fisher $(20)$.

\section{RESULTS}

The data are recorded in Tables I and II. The responses to tilting are compared in Tables III and IV.

Right atrial pressure. Right atrial mean pressure increased when the dogs were tilted into the head-down position before ganglionic blockade. The increase averaged $1.4 \mathrm{~mm} \mathrm{Hg}$. The pressure in the supine position did not change consistently after ganglionic blockade, but tilting again led to an average increase of $1.4 \mathrm{~mm} \mathrm{Hg}$. The difference between the responses to tilting before and after trimethidinium (Table III) was not significant $(p<0.9)$. There was essentially no change in right atrial pressure (Table IV) when heart rate was restored electrically with the animal head-down.

In these experiments, changes in right atrial pressure (measured with respect to atmospheric pressure) are considered to reflect changes in transmural right atrial pressure. This was confirmed in three dogs by measuring atrial pressure with reference to intraesophageal pressure (which reflects intrapleural pressure) during tilting.

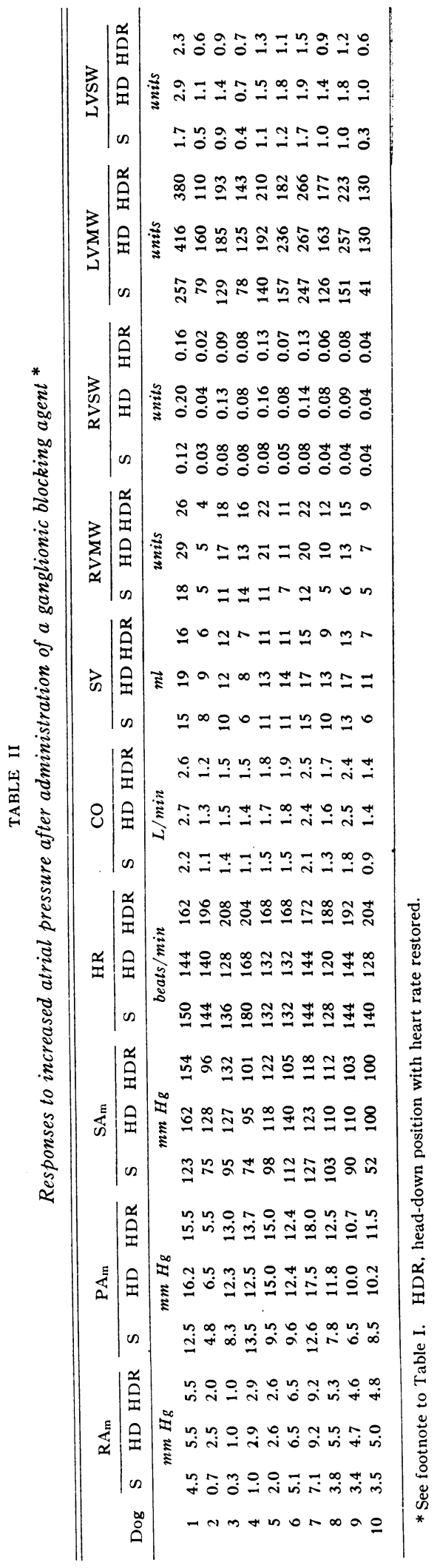



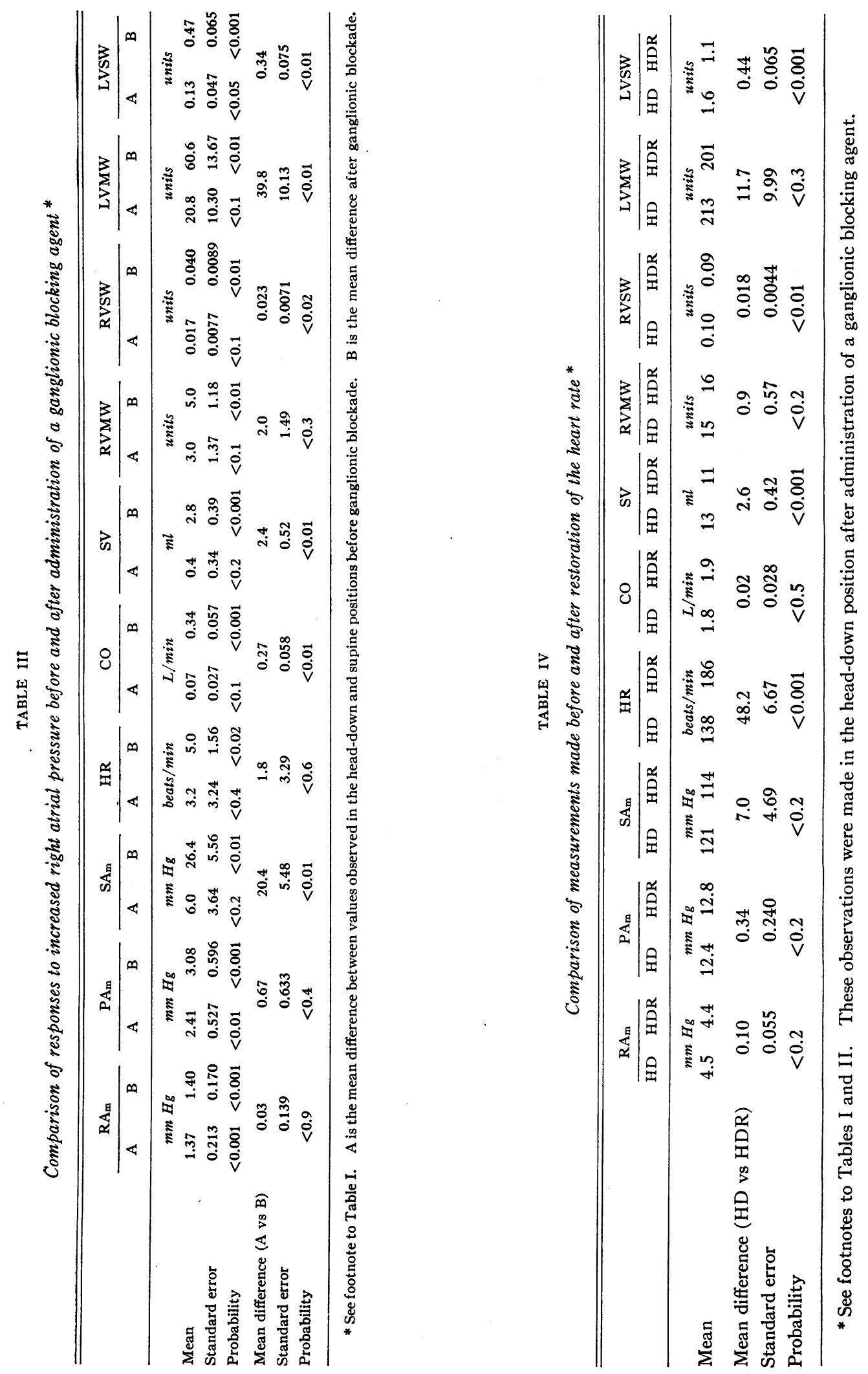
The close relationship between right atrial mean pressure and transmural pressure is not surprising. The dogs were ventilated with a respiratory pump that kept ventilatory rate and depth constant. Skeletal muscle relaxation was pronounced because of the gallamine, and tilting the dogs into the $20^{\circ}$ head-down position led to very little shift in abdominal contents. All of these factors tended to stabilize intrapleural pressure in this preparation.

Pulmonary arterial pressure. Pulmonary arterial mean pressure increased regularly with tilting. The increase averaged $2.4 \mathrm{~mm} \mathrm{Hg}$ before and $3.1 \mathrm{~mm} \mathrm{Hg}$ after trimethidinium. Pulmonary arterial pressure in the supine position was always reduced following ganglionic blockade. The response to tilting, however, was not altered significantly (Table III) by the blocking drug $(\mathrm{p}<$ 0.4 ). Increasing heart rate in the head-down position had an insignificant effect on the pressure $(\mathrm{p}<0.2)$.

Systemic arterial pressure. Femoral arterial mean pressure did not change appreciably with tilting before trimethidinium. After the drug, tilting led to an increase which averaged $26.4 \mathrm{~mm}$ $\mathrm{Hg}$. The increase in arterial pressure with tilting was significantly greater (Table III) after trimethidinium $(p<0.01)$. Increasing heart rate in the head-down position had an insignificant effect (Table IV) on the pressure $(\mathrm{p}<0.2)$.

Heart rate. The gallamine-prepared dog has a rapid heart rate. This is attributed to the vagolytic action of the drug (21) and in these experiments to the vagotomy. The sharp reduction in resting rate with trimethidinium is attributed to reduction in cardiac sympathetic tone in the presence of the vagotomy. The heart rate did not change much with tilting, and the difference between responses to tilting before and after ganglionic blockade (Table III) was not significant $(p<0.6)$. It was not possible in each instance to restore the rate exactly to the resting level by electrical stimulation. Failure to achieve the ideal rate occurred in animals whose resting rate was very rapid. The restored rate is the rate nearest to the resting value without irregularities in rhythm. The restored rate averaged 186 beats per minute, 13 less than the control.

Cardiac output and stroke volume. Cardiac output increased from an average of $2.5 \mathrm{~L}$ per minute in the supine position to only $2.6 \mathrm{~L}$ with tilting before administration of the blocking drug (Table I). Output in the supine position fell to an average of $1.5 \mathrm{~L}$ per minute after trimethidinium but increased to an average of $1.8 \mathrm{~L}$ with tilting (Table II). Although the resting output was lower, the response to tilting was appreciably greater (Table III) after ganglionic blockade $(p<0.01)$. Restoration of the heart rate with the dogs tilted had no effect on cardiac output.

Stroke volume (Table III) was essentially unchanged with tilting before trimethidinium. It increased an average of $2.8 \mathrm{ml}$ with tilting after the drug $(p<0.001)$, and fell by an average of $3.2 \mathrm{ml}$ with restoration of the heart rate in the head-down position $(p<0.001)$. The reduction in cardiac output with ganglionic blockade appears to be caused primarily by a fall in stroke volume rather than by a decrease in rate, since output remained lower than the control level even after the rate was restored.

Cardiac work. It is customary to describe the performance of the ventricles in terms of the external work they do. External work is represented as the product of stroke volume or minute volume and mean arterial pressure minus mean atrial pressure. These indices have been calculated and included in the tables. The values for minute work and stroke work tend to parallel the values for cardiac output and stroke volume.

\section{DISCUSSION}

Gallamine (21) is a muscle relaxant similar to curare. It does not, however, have the ganglionicblocking and histamine-releasing properties of the latter drug. Blood pressure is not depressed and consciousness and sensory function apparently are not disturbed. Cardiovascular responses to stimuli mediated over the autonomic nervous system are considered to be predominantly sympathetic in the preparation used in these experiments because of the vagotomy and the selective vagolytic action (21) of the gallamine. These dogs appear to have highly functional sympathetic pathways. Their cardiovascular responses to many stimuli are similar to those that might be observed in unanesthetized dogs. Light touch or unusual sounds within the room cause marked fluctuations in heart rate and blood pressure. Cardiac output has been observed to double or triple the resting level 
following an unusual noise or mildly painful stimulus.

Recent studies by Sarnoff (22) and others (35 ) indicate that changes in the performance of the heart muscle are related to the degree of sympathetic stimulation. At a constant heart rate, increased sympathetic stimulation of the myocardium causes the heart to do more work at a lower filling pressure (3). It appears that withdrawal of sympathetic tone from the heart might cause it to do less work at a higher filling pressure. The results of the experiments reported here fit these concepts of the regulation of myocardial function. In the presence of intact sympathetic pathways, the heart failed to increase its work output significantly when atrial pressure increased. After sympathetic tone was removed by ganglionic blockade, the heart responded more clearly to an increase in filling pressure. In the first instance, failure of output to increase with the increase in filling pressure may mean that sympathetic tone to the myocardium is withdrawn, possibly by some reflex mechanism. The net effect of such a reflex might be a new relationship between atrial pressure and ventricular function (higher pressure and reduced function) which results in no change in output or external work of the heart. In the second situation, pharmacologic denervation appeared to remove the sympathetic influence which normally alters myocardial performance. It became impossible for the effect of the increased filling pressure to be modified by a reduction in the functional characteristics of the heart muscle. The result of such denervation is a heart that increases its output with an increase in filling pressure. Such behavior resembles that of a heartlung preparation.

The administration of trimethidinium led to reduction in the supine levels of cardiac output, stroke volume and ventricular work. Significant increase in output and work were noted when filling pressure was increased. Despite these increases, the levels seen before ganglionic blockade were not achieved. Even restoration of the heart rate caused no further increase in cardiac output or minute work of the ventricles. Recent studies suggest that the reduced cardiac output associated with ganglionic blocking drugs is not the result of myocardial depression (23). Some believe that the fall in output is caused primarily by venous pooling $(24,25)$. Beck (26), however, has demonstrated clearly in intact dogs that cardiac output falls with hexamethonium administration even if atrial pressure is held constant. The experiments reported here support those of Beck and indicate that the fall in output after administration of ganglionic blocking drugs may be attributed, at least in part, to changes in myocardial function. The reduced cardiac output following ganglionic blockade when filling pressure is controlled is caused primarily by the fall in stroke volume, since restoring heart rate to the control level leaves the minute volume unchanged.

In these experiments the fall in cardiac output and work is attributed to a reduction in the inflow of sympathetic impulses to the myocardium. The possibility remains that the decrease in cardiac function might be related to a direct depressant action of trimethidinium on the heart muscle. We have not been able to find evidence in the literature that would suggest that ganglionic blocking drugs depress the myocardium directly. Beck (26) also has been unable to find such evidence. He cites the work of Acheson and Moe (27), who found that tetraethyl ammonium increases the output of the heart-lung preparation. Lee and Shideman (28) found that the positive inotropic effect on the myocardium, produced by ganglionic stimulating drugs, could be blocked by ganglionic blocking agents. The available evidence indicates that the myocardial "depressant" effects of ganglionic blocking agents are related to blockade of nervous impulses and not to a direct action on the muscle.

\section{SUM MARY}

The ventricular responses to the increased filling pressure produced by tilting into the headdown position were studied in 10 vagotomized dogs treated with gallamine. Before administration of a ganglionic blocking agent there were only slight changes in heart rate, cardiac output, stroke volume and external work of the ventricles in response to the rise in pressure. After cardiac sympathetic tone was reduced by administration of a ganglionic blocking drug (trimethidinium) heart rate, cardiac output, stroke volume and ventricular work fell. Increasing atrial pressure 
caused significant increases in output and work, but the levels present before trimethidinium were not achieved. Restoration of the heart rate by electrical stimulation of the atrium with the animals in the head-down position caused no further increase in cardiac output or work.

It is suggested that increased atrial pressure in the presence of an intact sympathetic nervous system causes little change in the work output of the heart because of reflex withdrawal of sympathetic tone to the myocardium. Pharmacologic denervation of the heart appears to remove this sympathetic influence which might otherwise modify the effect of an increased filling pressure. The denervated heart responds more clearly to an increase in filling pressure. In this respect its performance resembles that of a heart-lung preparation.

\section{REFERENCES}

1. Shipley, R. E., and Gregg, D. E. The cardiac response to stimulation of the stellate ganglia and cardiac nerves. Amer. J. Physiol. 1945, 143, 396.

2. Anzola, J., and Rushmer, R. F. Cardiac responses to sympathetic stimulation. Circulat. Res. 1956, 4, 302 .

3. Sarnoff, S. J., Brockman, S. K., Gilmore, J. P., Mitchell, J., and Linden, R. J. The influence of carotid sinus pressure on myocardial contractility. Fed. Proc. 1959, 18, 137.

4. Brockman, S. K., Linden, R. J., Mitchell, J., Gilmore, J. P., and Sarnoff, S. J. The effect of vagal stimulation on ventricular function. Fed. Proc. 1959, $18,17$.

5. Sarnoff, S. J., Mitchell, J. H., and Gilmore, J. P. The effect of changes in atrial systole on the relation between mean atrial pressure and stroke work (abstract). J. clin. Invest. 1960, 39, 1025.

6. Ferguson, T. B., Shadle, O. W., and Gregg, D. E. Effect of blood and saline infusion on ventricular end diastolic pressure, stroke work, stroke volume and cardiac output in the open and closed chest dog. Circulat. Res. 1953, 1, 62.

7. Gowdey, C. W., Hatcher, J. D., and Sunahara, F. A. Cardiovascular responses in dogs to large intravenous infusions. Canad. J. Biochem. 1954, 32, 282.

8. Sunahara, F. A., Hatcher, J. D., Beck, L., and Gowdey, C. W. Cardiovascular responses in dogs to intravenous infusions of whole blood, plasma, and plasma followed by packed erythrocytes. Canad. J. Biochem. 1955, 33, 349.

9. Gregg, D. E., Sabiston, D. C., and Theilen, E. O. Performance of the heart: Changes in left ventricular end-diastolic pressure and stroke work during infusion and following exercise. Physiol. Rev. 1955, 35, 130.

10. Stead, E. A., Jr., and Warren, J. V. Cardiac output in man. An analysis of the mechanisms varying the cardiac output based on recent clinical studies. Arch. intern. Med. 1947, 80, 237.

11. Stead, E. A., Jr., Brannon, E. S., Merrill, A. J., and Warren, J. V. Concentrated human albumin in the treatment of shock. Arch. intern. Med. 1946, 77, 564.

12. Schnabel, T. G., Jr., Eliasch, H., Thomasson, B., and Werkö, L. The effect of experimentally induced hypervolemia on cardiac function in normal subjects and patients with mitral stenosis. J. clin. Invest. 1959, 38, 117.

13. Sancetta, S. M. Acute hemodynamic effects of total head-down body tilt and hexamethonium in normal and pulmonary emphysematous subjects. J. Lab. clin. Med. 1957, 49, 684.

14. Goldstein, A., and Aronow, L. The durations of action of thiopental and pentobarbital. J. Pharmacol. exp. Ther. 1960, 128, 1.

15. Price, H. L. A dynamic concept of the distribution of thiopental in the human body. Anesthesiology 1960, 21, 40.

16. O'Malley, W. E., Haemmerli, G. W., Rice, L. M., and Gesickter, C. F. Studies on the antihypertensive action of $\mathrm{N}$-dimethylamino-propyl-1-methyl8, 8-dimethyl-3-azobicyclo $(3,2,1)$ octane dimethochloride (Wy-1395). J. Amer. Pharm. Ass., sci. ed. 1958, 47, 263.

17. Eckfeld, D. K., Tislow, R., and Seifter, J. Hypotensive properties of some asymmetrical bis-quaternary compounds (abstract). J. Pharmacol. exp. Ther. 1958, 122, $21 \mathrm{~A}$.

18. Hosko, M. J., Townsend, P., Tislow, R., and Seifter, J. Hypotensive and ganglionic blocking properties of d-N-dimethylamino-propyl-1-methyl-8, 8-dimethyl-3-azobicyclo $(3,2,1)$ octane dimethosulfate (abstract). J. Pharmacol. exp. Ther. 1958, 122, 33A.

19. Kirkendall, W. M., Armstrong, M. L., Funk, D. C., and Theilen, E. O. Acute effects of trimethidinium methosulfate (WY-1395) on blood pressure, cardiac output, renal hemodynamics, and pulse rate in man (abstract). Circulation 1958, 18, 743.

20. Fisher, R. A. Statistical Methods for Research Workers, 10th ed. Edinburgh, Oliver and Boyd, 1946.

21. Goodman, L. S., and Gilman, A. The Pharmacological Basis of Therapeutics, 2nd ed. New York, Macmillan, 1955, p. 616.

22. Sarnoff, S. J. Certain aspects of the role of catecholamines in circulatory regulation. Amer. $\mathbf{J}$. Cardiol. 1960, 5, 579.

23. Rowe, G. W., Castillo, C. A., Maxwell, G. M., White, D. H., Jr., Freeman, D. J., and Crumpton, C. W. The effect of mecamylamine on coronary 
flow, cardiac work, and cardiac efficiency in normotensive dogs. J. Lab. clin. Med. 1958, 52, 883.

24. Crosley, A. P., Jr., Brown, J. F., Tuchman, H., Crumpton, C. W., Huston, J. H., and Rowe, G. G. The acute hemodynamic and metabolic response of hypertensive patients to pentolinium tartrate. Circulation 1956, 14, 584.

25. Smith, J. R., and Hoobler, S. W. Acute and chronic cardiovascular effects of pentolinium on hypertensive patients. Circulation 1956, 14, 1061.
26. Beck, L. Effect of the autonomic nervous system on arteriolar tone in the experimental animal. Circulation 1958, 17, 798.

27. Acheson, G. H., and Moe, G. K. Some effects of tetraethyl ammonium on the mammalian heart. J. Pharmacol. exp. Ther. 1945, 84, 189.

28. Lee, W. C., and Shideman, F. E. Mechanism of the positive inotropic response to certain ganglionic stimulants. J. Pharmacol. exp. Ther. 1959, 126, 239. 